\title{
Rare Nivolumab-associated Super Hyper Progressive Disease in Patients With Advanced Gastric Cancer
}

\author{
YUTARO KUBOTA ${ }^{1}$, KIYOSHI YOSHIMURA ${ }^{1,2}$, KAZUYUKI HAMADA ${ }^{1}$, YUYA HIRASAWA ${ }^{1}$, \\ MIDORI SHIDA $^{2}$, MAKOTO TANIGUCHI ${ }^{2}$, HIROTO MATSUI ${ }^{3}$, HIROTSUGU ARIIZUMI ${ }^{1}$, \\ TOMOYUKI ISHIGURO ${ }^{1}$, NORIHIRO SUZUKI ${ }^{4}$, RYOTARO OHKUMA ${ }^{1}$, TAKEHIKO SAMBE ${ }^{5}$, \\ HIROO ISHIDA ${ }^{1}$, ATSUSHI HORIIKE ${ }^{1}$, SATOSHI WADA ${ }^{1,6}$, JUNJI TSURUTANI ${ }^{1,7}$, SANJU IWAMOTO $^{8}$, \\ NAOKI UCHIDA ${ }^{5}$, YUJI KIUCHI ${ }^{9}$, SHINICHI KOBAYASHI ${ }^{10}$ and TAKUYA TSUNODA ${ }^{1}$ \\ ${ }^{1}$ Division of Medical Oncology, Department of Medicine, Showa University School of Medicine, Tokyo, Japan; \\ ${ }^{2}$ Department of Clinical Immuno-Oncology, Clinical Research Institute \\ for Clinical Pharmacology and Therapeutics, Showa University, Tokyo, Japan; \\ ${ }^{3}$ Department of Gastroenterological, Breast and Endocrine Surgery, \\ Yamaguchi University Graduate School of Medicine, Yamaguchi, Japan; \\ ${ }^{4}$ Division of Gastroenterology, Department of Medicine, Showa University School of Medicine, Tokyo, Japan; \\ ${ }^{5}$ Division of Clinical Pharmacology, Department of Pharmacology, \\ Showa University School of Medicine, Tokyo, Japan; \\ ${ }^{6}$ Department of Clinical Diagnostic Oncology, Clinical Research Institute \\ for Clinical Pharmacology and Therapeutics, Showa University, Tokyo, Japan; \\ ${ }^{7}$ Advanced Cancer Translational Research Institute, Showa University, Tokyo, Japan; \\ ${ }^{8}$ Department of Biochemistry, Showa University School of Medicine, Tokyo, Japan; \\ ${ }^{9}$ Department of Pharmacology, Showa University School of Medicine, Tokyo, Japan; \\ ${ }^{10}$ Clinical Research Institute for Clinical Pharmacology and Therapeutics, Showa University, Tokyo, Japan
}

\begin{abstract}
Background/Aim: Rapid tumor growth after administration of immune checkpoint inhibitors is designated hyper progressive disease (HPD). In this study, besides the conventional HPD category, we proposed the "super HPD" category where the disease is naturally rapidly growing. Patients and Methods: Patients treated for advanced gastric cancer with irinotecan or nivolumab as a third-line treatment were retrospectively compared. Results: Eighteen and 26 patients were treated with irinotecan or nivolumab, respectively. There were 3 HPD cases (16.7\%) in the irinotecan group, 6 cases $(23.1 \%)$ in the nivolumab group, and the frequency of HPD was not significantly different.
\end{abstract}

This article is freely accessible online.

Correspondence to: Prof. Kiyoshi Yoshimura, Department of Clinical Immuno-Oncology, Clinical Research Institute for Clinical Pharmacology and Therapeutics, Showa University, 6-11-11 Kitakarasuyama, Setagaya-ku, Tokyo, Japan. E-mail: kyoshim1@med.showa-u.ac.jp

Key Words: Hyper-progressive disease, gastric cancer, nivolumab, regulatory $\mathrm{T}$ cell.
Two cases satisfied the super HPD definition only in the nivolumab group. When one of them was analyzed immunologically, the number of regulatory $T$ cells was found to be increased, resulting in a low neutrophil-to-lymphocyte ratio. Conclusion: Our proposed super HPD was likely to represent a true HPD, with a frequency of $7.7 \%$.

In 2012, phase I clinical trials of anti-PD-1 antibody and anti-PD-L1 antibody for solid cancer were conducted $(1,2)$. Since then, clinical development has progressed, and these antibodies have been shown to be effective in many cancer types. In gastric cancer, the ATTRACTION-2 trial has shown a survival benefit of nivolumab, an anti-PD-1 antibody, compared to placebo after two or more lines of chemotherapy (3). Consequently, nivolumab is recommended for third-line chemotherapy according to the Japanese guidelines. Further, the single-arm phase II KEYNOTE-059 trial has demonstrated the effectiveness of pembrolizumab, another anti-PD-1 antibody, in the same setting (4), and pembrolizumab was more effective in PD-L1 positive (Combined positive score: $\mathrm{CPS} \geq 1$ ) tumors compared to PDL1 negative $(\mathrm{CPS}<1)$ tumors. Accordingly, pembrolizumab has been adopted as a third-line or subsequent therapy for gastric cancer according to the National Comprehensive 
Cancer Network (NCCN) guidelines. Furthermore, pembrolizumab showed efficacy in tumors with mismatchrepair deficiency (dMMR) in the phase II trial (5). Although only one gastric cancer patient was involved in this trial, NCCN guidelines recommend pembrolizumab for patients with dMMR gastric cancer.

While an effect has been shown, a case of rapid tumor growth after administration of immune checkpoint inhibitors (ICI) such as nivolumab or pembrolizumab has been reported and this condition is designated hyper progressive disease (HPD). In the second-line setting of gastric cancer, the KEYNOTE-061 trial showed an earlier decline in the survival curve in the pembrolizumab group compared to the paclitaxel group, whose survival curve showed a gradual increase (6). Similar effects were observed in the KEYNOTE-062 trial that investigated the efficacy of pembrolizumab, platinum plus fluoropyrimidine, and both, in the first line setting (7). This early decline in the survival curve in the pembrolizumab group suggested the possibility of HPD cases. HPD has been reported in various cancers $(8$, $9)$, such as non-small cell lung $(10,11)$, head and neck (12), and gastric cancer $(13,14)$, with a rate between $6 \%$ and $29 \%$. Although there is no clear definition of HPD, it is common for HPD to have a tumor growth kinetics (TGK) ratio of 2 or more (12). However, rapid tumor growth often occurs with the use of cytotoxic agents in daily clinical practice, especially in the late lines of chemotherapy. Furthermore, this rapid growth can occur in the natural course of tumors. The true HPD mechanism is immunospecific, which cannot occur when using a cytotoxic agent. Thus, HPD occurrence due to cytotoxic agents probably reflects growth during the natural course of disease. The above HPD criteria can be satisfied even in these cases.

Two retrospective studies have reported that the frequency of HPD with nivolumab administration in gastric cancer was $20 \%$ (13) and $29.4 \%$ (14). These cases may contain cases of rapid tumor growth in the natural course not related to ICI administration, resulting in an overestimation of the actual HPD cases in the previous reports. In the case of true HPD cases, administration of ICI accelerated the progression of the tumor and rapidly deteriorated the condition. Therefore, it was very important to understand the frequency and predict in advance the occurrence of HPD.

Sasaki et al. have retrospectively investigated gastric cancer patients who were treated with nivolumab after two or more lines of chemotherapy. They reported that Eastern Cooperative Oncology Group performance status (ECOG PS) of 1 or 2, liver metastases, a large sum of target lesion diameters, and the elevation of absolute neutrophil count (ANC) and C-reactive protein (CRP) after initiation of nivolumab were significantly correlated with HPD (13). In other cancer types, Ferrara et al. reported that HPD was significantly associated with more than two metastatic sites compared to non-HPD in non-small cell lung cancer (10). Although we should have considered these clinical features before treatment, it was difficult to accurately predict HPD before ICI administration using these factors.

Regarding the molecular features of HPD cases, Kato et al. reported that $M D M 2 / 4$ amplification and EGFR aberration were associated with HPD (9). Additionally, Lo Russo et al. reported that CD33 and CD163 were associated with HPD (11). However, these molecular features are wellknown factors that suggest resistance to ICI and do not necessarily cause HPD. Accordingly, there are no molecular biomarkers predicting HPD at this time.

Therefore, we retrospectively compared patients who received nivolumab and or irinotecan as a third-line treatment for gastric cancer in our hospital and investigated the frequency of HPD using the above general criteria. We proposed to terminate the concept of true HPD and replace it with that of super HPD. We then generated criteria for super HPD and investigated its frequency. In addition, immunological analysis was performed before and after treatment of nivolumab-treated cases. The relationship between immune cell dynamics and the treatment effect was examined.

\section{Patients and Methods}

Patients. Patients treated for unresectable advanced or recurrent gastric cancer with irinotecan as a third-line treatment from January 2014 to October 2017 or nivolumab from October 2017 to March 2019 were retrospectively compared. Of these, patients who met the following criteria were included: 1) histologically confirmed gastric or esophago-gastric junction adenocarcinoma, 2) an ECOG performance status (PS) of 0-2, and 3) computed tomography (CT) findings within 3 months before and after treatment. We did not ask for the presence or absence of a measurable lesion, because some advanced gastric cancers, particularly in undifferentiated type, had only peritoneal dissemination but no measurable lesions. As for post-treatment, any treatment was permitted. Evaluation factors were the presence or absence of HPD and super HPD, overall response rate, progression-free survival (PFS), and overall survival (OS). Response rate was calculated according to RECIST ver1.1 to evaluate the best overall response. In patients without measurable lesion, the effect was evaluated according to the criteria for evaluation of non-target lesions, such as complete response (CR), non-CR/non-PD, and progressive disease (PD), based on first evaluated CT. PFS was defined as the interval between the date of the first drug administration and the date of disease progression or to the date of death from any cause. OS was the period from the start of third-line treatment to the date of death from any cause.

Definition of HPD and super HPD. The definition of HPD for patients who had target lesions was set to TGK ratio 2 or higher based on the previous report (12). The pre-baseline CT, baseline CT, and post-treatment first $\mathrm{CT}$ were defined as $\mathrm{T}_{\text {pre }}, \mathrm{T}_{0}$, and $\mathrm{T}_{\text {post }}$, respectively. The sums of the largest diameters of the target lesions at pre-baseline CT, baseline CT, and post-treatment first CT were defined as $S_{\text {pre }}, S_{0}$, and $S_{\text {post }}$, respectively. We included the patients who did not have measurable lesions. If the longest diameter of the 
largest metastatic lesion was less than $10 \mathrm{~mm}$, or the shortest diameter of the largest lymph node was less than $15 \mathrm{~mm}$, we used the measured value itself for TGK analysis. TGK pre and $\mathrm{TGK}_{\text {post }}$ were calculated as $\left(\mathrm{S}_{0}-\mathrm{S}_{\text {pre }}\right) /\left(\mathrm{T}_{0}-\mathrm{T}_{\text {pre }}\right)$, and $\left(\mathrm{S}_{\text {post }}-\mathrm{S}_{0}\right) /\left(\mathrm{T}_{\text {post }} \mathrm{T}_{0}\right)$. TGK ratio was defined as the ratio of $\mathrm{TGK}_{\text {post }}$ to $\mathrm{TGK}_{\mathrm{pre}}$. However, there were cases where lesions could not be measured, such as peritoneal metastases and/or malignant ascites, in which HPD was defined by the following methods during the four weeks after nivolumab administration: 1) cases whose ascites thickness $(\mathrm{mm})$ on the surface of the liver or peritoneal dissemination thickness $(\mathrm{mm})$ increased two times or more, or 2) cases that developed intestinal obstruction due to peritoneal dissemination.

To distinguish natural course cases from HPD, cases with TGK ratio of 5 or more and an increase in the number of tumors two times or more compared to the pre-baseline number of tumors were defined as super HPD. In patients who did not have a measurable lesion, we defined the cases with rapid progression of peritoneal dissemination and development of intestinal obstruction within 2 weeks after nivolumab administration as super HPD.

Immunological and molecular examination. Immunological study was performed using five patients who received nivolumab. Their blood samples were collected before and after treatment. One case was a super HPD case, two cases were normal HPD cases, and two cases were long stable disease (SD) cases. In conventional HPD cases and long SD cases, blood samples were collected before, 2 weeks and 4 weeks after nivolumab administration. In the super HPD case, blood samples could not be collected before treatment. Thus, we decided to use the samples of 2 weeks and 4 weeks after treatment. We performed population kinetic studies on a subset of immune cells using flow cytometry as an immunological study. In the super HPD case, we collected a tumor sample during gastroscopy to evaluate the primary site after super HPD, with patient consent.

Peripheral blood mononuclear cells (PBMCs) of each patient were harvested by density gradient centrifugation with Ficoll-Paque (Amersham Pharmacia Biotech, Uppsala, Sweden). PBMCs were stained using human PerCP-Cy5-conjugated human CD4 Ab, V500conjugated human CD3 Ab, APC-conjugated human FoxP3 Ab, (BD Biosciences, San Jose, CA, USA) FITC-conjugated human CD45RA Ab (Miltenyi Biotec, Bergisch Gladbach, North RhineWestphalia, Germany), V450-conjugated human CTLA-4 Ab (BD Biosciences), PE-conjugated human MCAM Ab (BD Biosciences), and Alexa Fluor 488-conjugated human CD161 Ab (BD Biosciences). Cells were stained according to manufacturer's flow cytometry preparation protocol for each antibody, and the staining was detected using the BD LSRFORTESSA X-2 flow cytometer (BD Biosciences). Flow cytometric data were analyzed using FlowJo software, version 10.3.0 (FlowJo, Ashland, OR, USA). The scale of the $\mathrm{Y}$ axis demonstrates the delta (D) mean fluorescent intensity (MFI). D MFI was calculated by subtracting the control MFI from the MFI

Statistical analysis. Associations between two groups of categorical and continuous variables and two groups of categorical variables were analyzed by the Wilcoxon test and Chi-square test, respectively. PFS and OS were calculated by the Kaplan-Meier method. All analyses were performed using JMP software, version 14.0 (SAS Institute, Cary, NC, USA). Correlations or associations were considered to be statistically significant when the two-tailed $p$-value was less than 0.05 .
Table I. Patients' characteristics.

\begin{tabular}{|c|c|c|c|}
\hline & $\begin{array}{l}\text { Nivolumab } \\
\quad(n=26)\end{array}$ & $\begin{array}{l}\text { Irinotecan } \\
\quad(\mathrm{n}=18)\end{array}$ & $p$-Value \\
\hline Age, median (range) & $65(25-82)$ & $67.5(47-80)$ & 0.35 \\
\hline \multicolumn{4}{|l|}{ Gender } \\
\hline Male (\%) & $17(65 \%)$ & $10(56 \%)$ & \multirow[t]{2}{*}{0.54} \\
\hline Female $(\%)$ & $9(35 \%)$ & $8(44 \%)$ & \\
\hline \multicolumn{4}{|l|}{ ECOG PS } \\
\hline $0 / 1$ & $14(54 \%)$ & $14(78 \%)$ & \multirow[t]{2}{*}{0.13} \\
\hline 2 & $12(46 \%)$ & $4(22 \%)$ & \\
\hline \multicolumn{4}{|l|}{ Histology } \\
\hline Intestinal (\%) & $11(42 \%)$ & $9(50 \%)$ & \multirow[t]{3}{*}{0.38} \\
\hline Diffuse $(\%)$ & $15(58 \%)$ & $8(44 \%)$ & \\
\hline Unknown & $0(0 \%)$ & $1(6 \%)$ & \\
\hline \multicolumn{4}{|l|}{ HER2 } \\
\hline Positive (\%) & $5(19 \%)$ & $2(11 \%)$ & \multirow[t]{2}{*}{0.47} \\
\hline Negative (\%) & $21(82 \%)$ & $16(89 \%)$ & \\
\hline NLR, median (range) & $2.8(0.8-9.2)$ & $3.1(0.7-18.2)$ & 0.62 \\
\hline PLR, median (range) & $65.1(31.0-140.4)$ & $68.9(15.5-149.6)$ & 0.98 \\
\hline \multicolumn{4}{|l|}{ Metastatic site } \\
\hline Liver $(\%)$ & $10(38 \%)$ & $9(50 \%)$ & 0.54 \\
\hline Lung $(\%)$ & $0(0 \%)$ & $2(11 \%)$ & 0.16 \\
\hline Peritoneum (\%) & $15(58 \%)$ & $5(28 \%)$ & 0.07 \\
\hline Lymph node (\%) & $16(62 \%)$ & $14(78 \%)$ & 0.26 \\
\hline Other $(\%)$ & $6(23 \%)$ & $4(22 \%)$ & 1.00 \\
\hline \multicolumn{4}{|l|}{ Measurable lesion } \\
\hline$+(\%)$ & $15(58 \%)$ & $13(72 \%)$ & 0.36 \\
\hline$-(\%)$ & $11(42 \%)$ & $5(28 \%)$ & \\
\hline $\begin{array}{l}\text { The sum of the target } \\
\text { lesion diameter, } \\
\text { median (range) }\end{array}$ & $31(10-82)$ & $32(10-84)$ & 0.71 \\
\hline
\end{tabular}

ECOG PS: Eastern Cooperative Oncology Group performance status; HER2: human epidermal growth factor receptor 2; NLR: neutrophillymphocyte ratio; PLR: platelet-lymphocyte ratio.

This study was reviewed and approved by the Ethics Committee of Showa University School of Medicine.

\section{Results}

Patient characteristics. Eighteen patients were treated with irinotecan as a third-line treatment for unresectable advanced or recurrent gastric cancer from January 2014 to October 2017. In 26 cases, patients were administered with nivolumab as the third-line treatment from October 2017 to March 2019. Table I shows the clinicopathological features of each group. The nivolumab group included $17(65 \%)$ men and $9(35 \%)$ women, with a median age of 65 years (range $=25-82$ years). The irinotecan group consisted of $10(56 \%)$ men and 8 (44\%) women, with a median age of 67.5 years (range $=47-80$ years). The patients with PS 2 tended to be more frequent in the nivolumab group (46\%) than the irinotecan group (22\%). For intestinal type and HER2-positive cases, $11(42 \%)$ and 5 $(19 \%)$ were in the nivolumab group, and $9(50 \%)$ and $8(44 \%)$ 
A

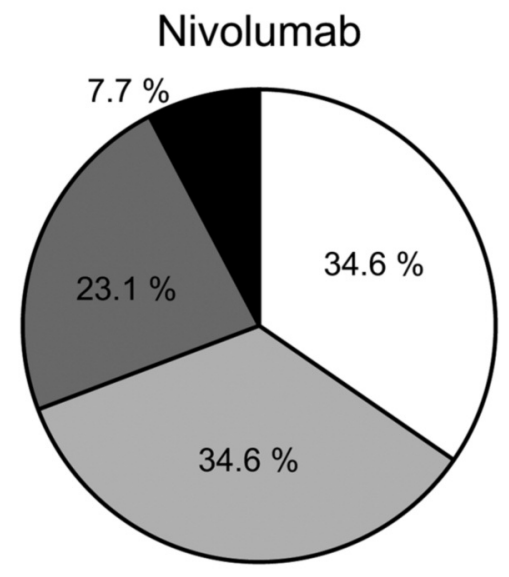

$\mathrm{PR}, \mathrm{SD}$, non-CR/non-PD

C

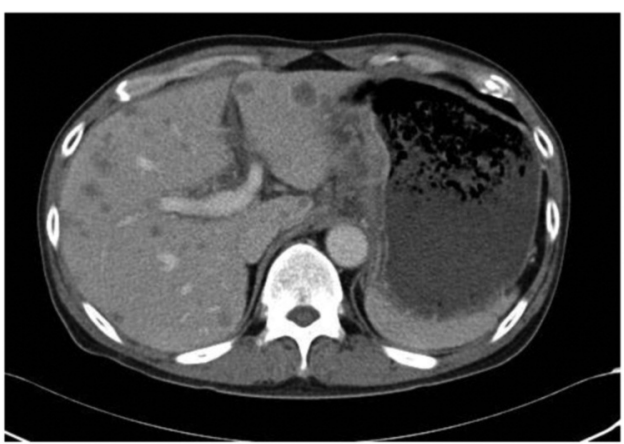

Before Nivolumab

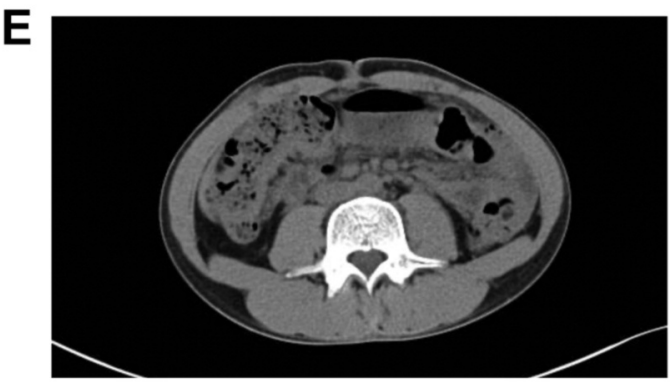

Before Nivolumab
B Irinotecan
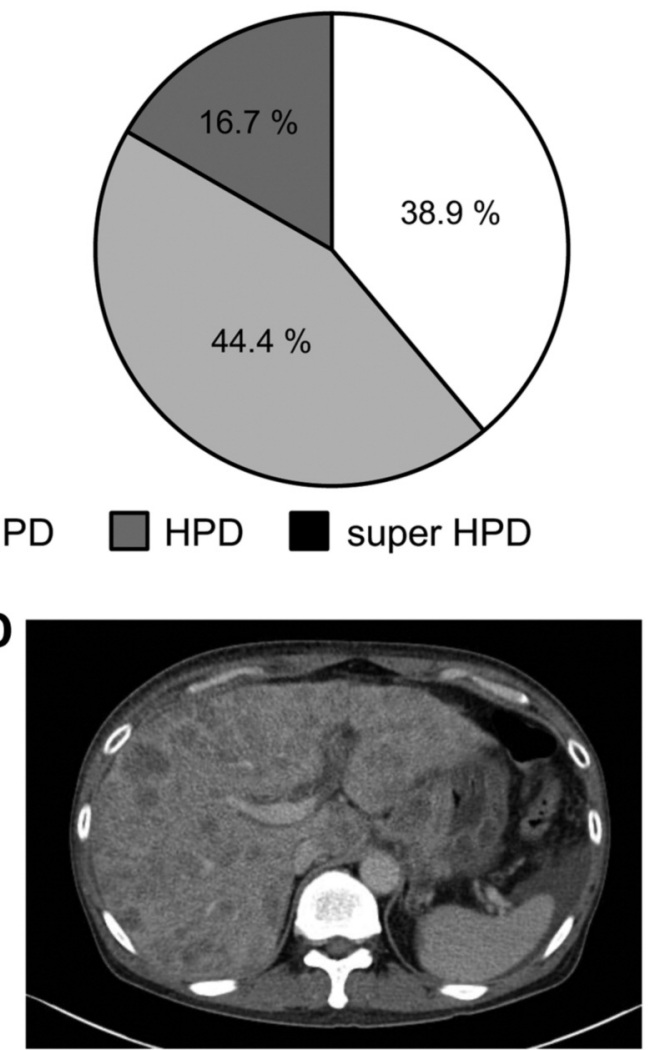

16 days after Nivolumab

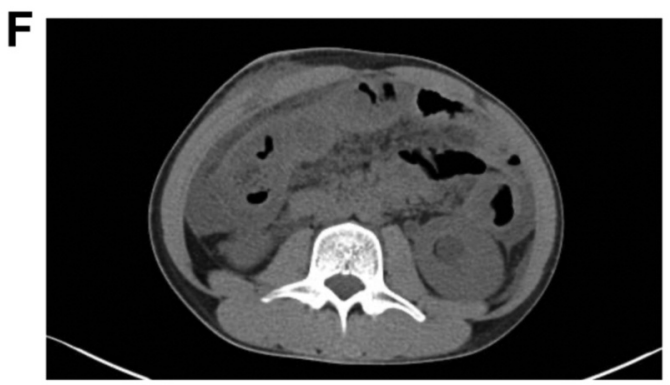

5 days after Nivolumab

Figure 1. Overall response and CT findings of super hyper-progressive disease (HPD) cases. Overall response of Nivolumab (A) and Irinotecan $(B)$. Case $1(C, D)$ showed increasing number of tumors two times or more resulting in tumor growth kinetics (TGK) ratio of 5.0 after nivolumab administration. Case $2(E, F)$, without a measurable lesion, developed rapid progression of peritoneal dissemination and development of bowel obstruction after nivolumab administration.

in the irinotecan group, respectively. Median neutrophillymphocyte ratio (NLR) and platelet-lymphocyte ratio (PLR) was 2.8 (range $=0.8-9.2)$ and $65.1($ range $=31.0-140.4)$ in the nivolumab group, 3.1 (range=0.7-18.2) and 68.9 (range=15.5149.6) in the irinotecan group. Further, 15 (58\%) patients had measurable lesions in the nivolumab group, whereas $13(72 \%)$ patients had measurable lesions in the irinotecan group. The sum of the target lesion diameter was $31 \mathrm{~mm}$ (range $=10-82$ $\mathrm{mm}$ ) in the nivolumab group and $32 \mathrm{~mm}$ (range $=10-84 \mathrm{~mm}$ ) in the irinotecan group. There was no significant difference in the background of both groups.

$H P D$ rate and response. Figure $1(\mathrm{~A}, \mathrm{~B})$ and Table II show therapeutic effects in both groups. The response rate (RR) 
Table II. Overall response to treatment.

Patients with measurable lesion

\begin{tabular}{lccc}
\hline & $\begin{array}{c}\text { Nivolumab } \\
(\mathrm{n}=15)\end{array}$ & $\begin{array}{c}\text { Irinotecan } \\
(\mathrm{n}=13)\end{array}$ & $p$-Value \\
\hline $\mathrm{CR}$ & $0(0 \%)$ & $0(0 \%)$ & \\
PR & $1(6.7 \%)$ & $4(30.8 \%)$ & \\
SD & $5(33.3 \%)$ & $2(15.4 \%)$ & \\
PD & $9(60.0 \%)$ & $7(53.8 \%)$ & \\
RR & $6.7 \%$ & $30.8 \%$ & 0.15 \\
DCR & $40.0 \%$ & $46.2 \%$ & 1.00 \\
HPD & $5(33.3 \%)$ & $3(16.7 \%)$ & 0.69 \\
Super HPD & $1(6.7 \%)$ & $0(0 \%)$ & 1.00 \\
\hline
\end{tabular}

Patients without measurable lesion

\begin{tabular}{lccc}
\hline & $\begin{array}{c}\text { Nivolumab } \\
(\mathrm{N}=11)\end{array}$ & $\begin{array}{c}\text { Irinotecan } \\
(\mathrm{N}=5)\end{array}$ & $p$-Value \\
\hline CR & $0(0 \%)$ & $0(0 \%)$ & \\
Non-CR/non-PD & $3(27.3 \%)$ & $\begin{array}{c}(20.0 \%) \\
\text { PD }\end{array}$ & $\begin{array}{l}(72.7 \%) \\
1(33.3 \%)\end{array}$ \\
HPD & $\begin{array}{l}0(0 \%) \\
0(0 \%)\end{array}$ & N/A $/ \mathrm{A}$ \\
Super HPD & & & \\
\hline Total patients & Nivolumab & Irinotecan & $p$-Value \\
\hline & $(\mathrm{N}=26)$ & $(\mathrm{N}=18)$ & \\
\hline HPD & $6(23.1 \%)$ & $3(16.7 \%)$ & 0.72 \\
Super HPD & $2(7.7 \%)$ & $0(0 \%)$ & 0.51 \\
\hline
\end{tabular}

CR: Complete response; PR: partial response; SD: stable disease; PD: progressive disease; NE: not evaluable; RR response rate; DCR: disease control rate; HPD: hyper-progressive disease.

and disease control rate (DCR) in the nivolumab group were $6.7 \%$ and $40.0 \%$, respectively, while $30.8 \%$ and $46.2 \%$ in the irinotecan group. There was no significant difference between the two groups. In the patients without measurable lesion, CR was not observed in both groups, non-CR/nonPD was observed $27.3 \%$ in the nivolumab group and $20.0 \%$ in the irinotecan group. There were 6 HPD cases $(23.1 \%)$ in the nivolumab group and 3 cases $(16.7 \%)$ in the irinotecan group. The frequency of HPD was not significantly different between the two groups. Two super HPD cases $(7.7 \%)$ satisfying our criteria were observed only in the nivolumab group. One super HPD case had a TGK ratio of 5 or more and an increase in the number of tumors 2 times or more compared to the pre-baseline number of tumors. The image findings before and after treatment for super HPD cases are shown in Figure 1. The patient had worsened general condition and increased aspartate aminotransferase (AST) and alanine aminotransferase (ALT) 16 days after
Table III. Patients' characteristics of HPD and non-HPD cases in the nivolumab group.

\begin{tabular}{|c|c|c|c|}
\hline & $\begin{array}{l}\mathrm{HPD} \\
(\mathrm{N}=6)\end{array}$ & $\begin{array}{l}\text { Non-HPD } \\
(\mathrm{N}=20)\end{array}$ & $p$-Value \\
\hline Age, median (range) & $68(25-82)$ & $62.5(49-82)$ & 0.63 \\
\hline \multicolumn{4}{|l|}{ Gender } \\
\hline Male (\%) & $6(100 \%)$ & $11(55 \%)$ & \multirow[t]{2}{*}{0.06} \\
\hline Female (\%) & $0(0 \%)$ & $9(45 \%)$ & \\
\hline \multicolumn{4}{|l|}{ PS } \\
\hline $0 / 1$ & $4(67 \%)$ & $10(50 \%)$ & \multirow[t]{2}{*}{0.65} \\
\hline 2 & $2(33 \%)$ & $10(50 \%)$ & \\
\hline \multicolumn{4}{|l|}{ Histology } \\
\hline Intestinal (\%) & $4(67 \%)$ & $7(35 \%)$ & \multirow[t]{2}{*}{0.35} \\
\hline Diffuse (\%) & $2(33 \%)$ & $13(65 \%)$ & \\
\hline \multicolumn{4}{|l|}{ HER2 } \\
\hline Positive (\%) & $3(50 \%)$ & $2(10 \%)$ & \multirow[t]{2}{*}{0.06} \\
\hline Negative (\%) & $3(50 \%)$ & $18(90 \%)$ & \\
\hline NLR, median (range) & $2.4(0.8-2.9)$ & $3.4(1.2-9.2)$ & 0.07 \\
\hline PLR, median (range) & $61.6(37.3-129.6)$ & $68.1(31.0-140.4)$ & 0.76 \\
\hline \multicolumn{4}{|l|}{ Metastatic site } \\
\hline Liver $(\%)$ & $5(83 \%)$ & $5(25 \%)$ & 0.02 \\
\hline Lung $(\%)$ & $0(0 \%)$ & $0(0 \%)$ & N/A \\
\hline Peritoneum (\%) & $3(50 \%)$ & $12(60 \%)$ & 1.00 \\
\hline Lymph node $(\%)$ & $4(67 \%)$ & $12(60 \%)$ & 1.00 \\
\hline $\begin{array}{l}\text { Diameter of measurable } \\
\text { lesion, median (range) }\end{array}$ & $27(3-73)$ & $21.5(8-37)$ & 0.90 \\
\hline
\end{tabular}

NLR: Neutrophil-lymphocyte ratio; PLR: platelet-lymphocyte ratio; HPD: hyper-progressive disease.

nivolumab administration. Therefore, when CT was performed, multiple liver metastases increased rapidly (Figure 1C, D). In another super HPD case, the peritoneal dissemination rapidly worsened, and the patient was unable to eat due to bowel obstruction 5 days after nivolumab administration (Figure 1E, F).

Progression free survival and overall survival. Median PFS was 1.6 months in the nivolumab group and 2.6 months the irinotecan group. Median OS was 3.8 months in the nivolumab group and 20.1 months in the irinotecan group (data not shown).

Immunological analysis. One out of 2 super HPD cases, 2 normal HPD cases, and 2 long SD cases were used for immunological analysis before and after treatment. The PFS of 2 long SD cases were 3.6 months and 6.7 months. The super HPD group was consistently higher than any natural HPD or long SD group in any subset of effector, central, and effector memory RA T cell (TEMRA) memory CD4-positive $\mathrm{T}$ cells (Figure 2). Levels of the Th17 population were similar in the super HPD, natural HPD, and long SD groups. Conversely, the regulatory $\mathrm{T}$ cell (Treg) population was highest in the super HPD group, whereas natural HPD and 
CD4+T cell

A

$\triangle \mathrm{MFI} \quad \mathrm{CD} 4+/$ central memory T cells

250.0

200.0

150.0

100.0

50.0

0.0

C

$\triangle \mathrm{MFI}$

200.0

150.0

100.0

50.0

0.0

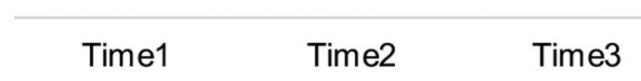

E

$\triangle \mathrm{MFI}$ CD4+/effector memory T cells

200.0

150.0

100.0

50.0

0.0

\section{CD4+/TEMRA}

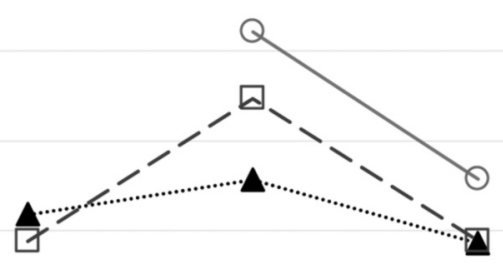

Time3
ローーーーー・ーーーーー曰

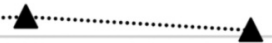

B

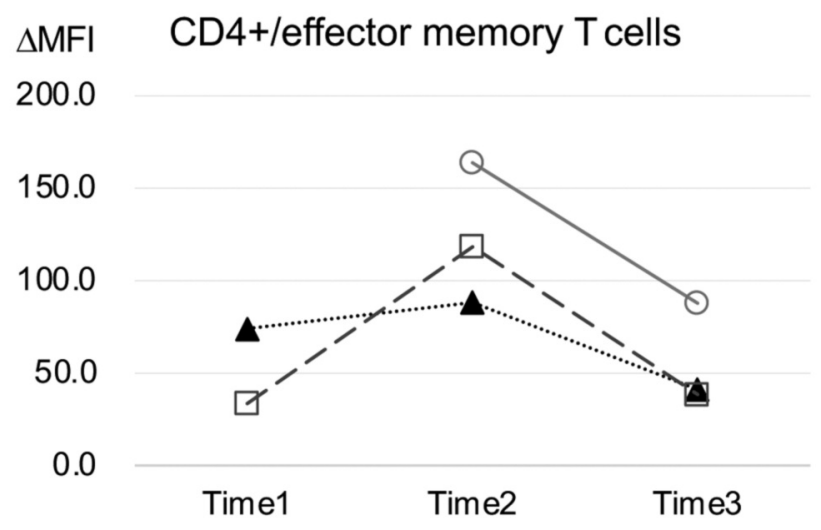

D

$\triangle \mathrm{MFI}$

250.0

200.0

150.0

100.0

$\mathbf{F}$

$\triangle \mathrm{MFI}$

200.0

150.0

100.0

Time2

Time3
50.0

0.0

\section{CD4+/central memory T cells}
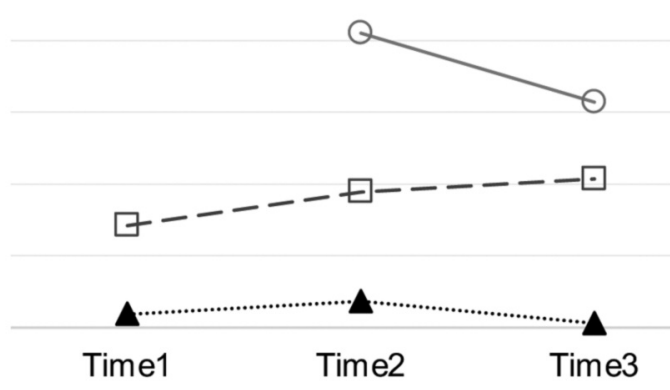

CD4+/TEMRA

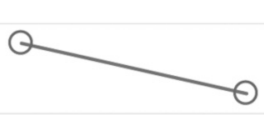

50.0

0.0

Figure 2. Immunological analyses of effector, central, and TEMRA memory CD4 positive T cells. Time 1 refers to before nivolumab administration. Time 2 and Time 3 refer to 2 and 4 weeks after nivolumab administration, respectively. Closed triangle, open square, and open circle showed long stable disease (SD) cases, conventional hyper-progressive disease (HPD) cases, and super HPD case, respectively. 


\section{Th17}
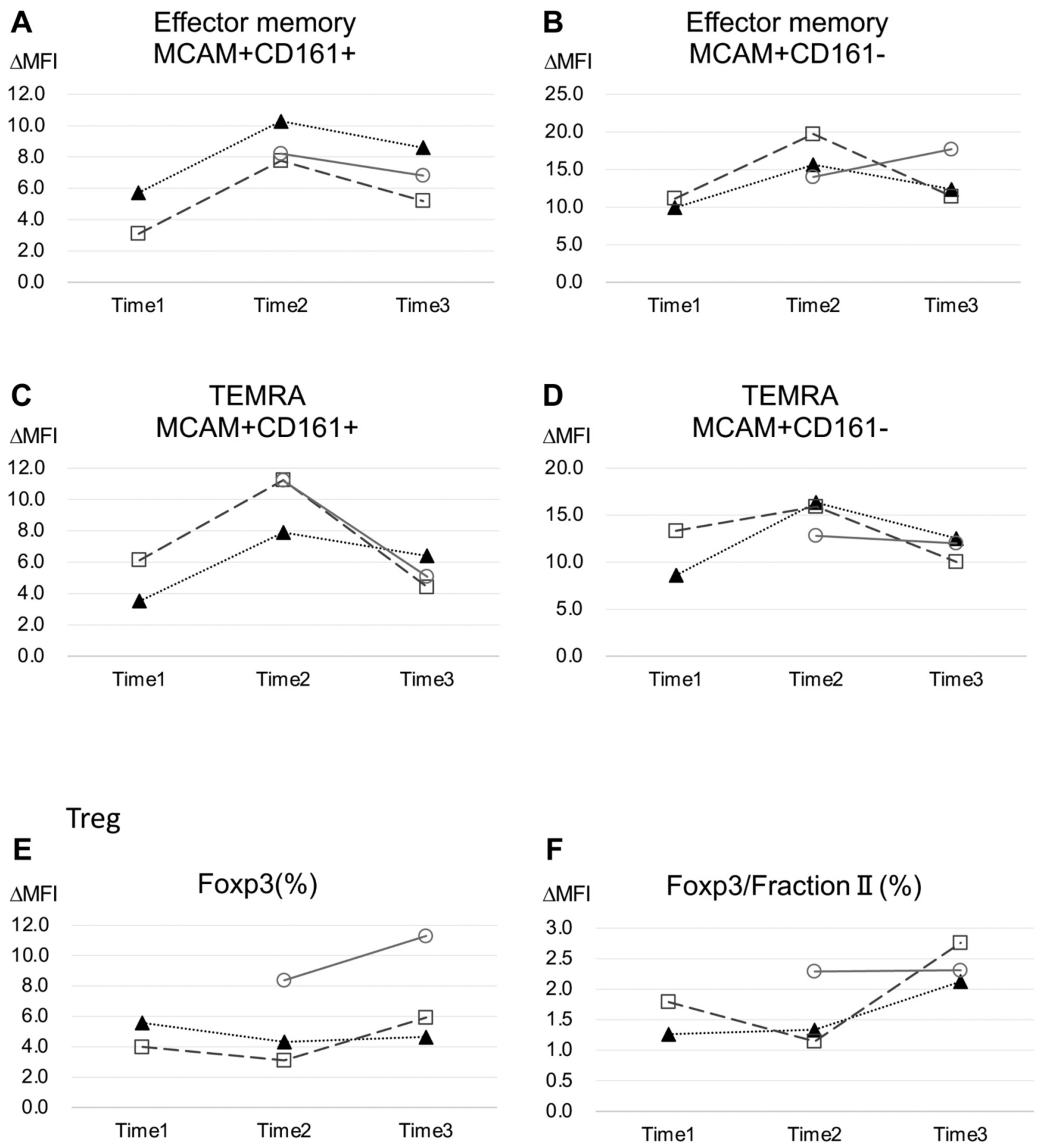

$\Delta$ Long SD $\square$ HPD O super HPD

Figure 3. Immunological analyses of Th17 and Treg. Time 1 refers to before nivolumab administration. Time 2 and Time 3 refer to 2 and 4 weeks after nivolumab administration, respectively. Closed triangle, open square, and open circle showed long stable disease (SD) cases, conventional hyper-progressive disease (HPD) cases, and super HPD case, respectively. 

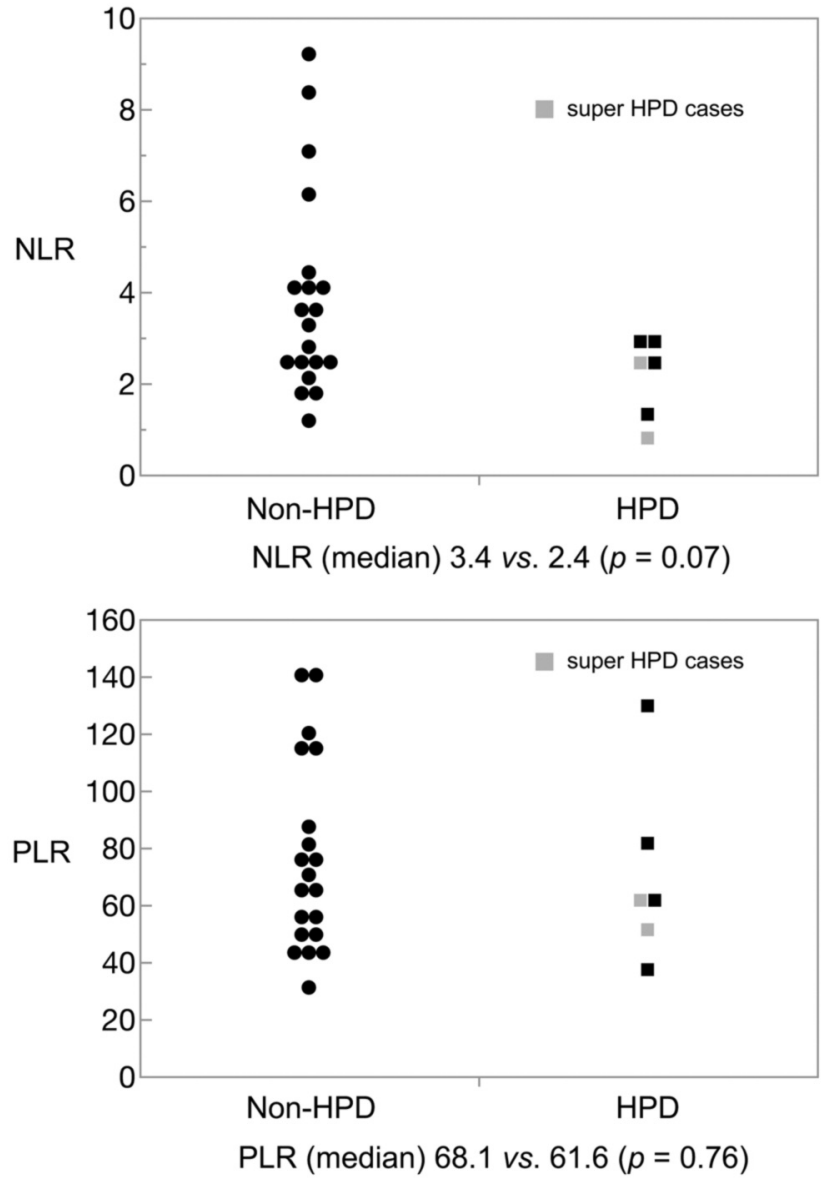

Figure 4. Neutrophil-lymphocyte ratio (NLR) and platelet-lymphocyte ratio $(P L R)$ in hyper-progressive disease (HPD) cases and non-HPD cases. Closed square and closed circle show HPD cases and non-HPD cases, respectively. Two cases of super HPD are marked grey square.

long SD levels were comparable, yet at a lower level to the super HPD group (Figure 3).

Comparison between HPD and non HPD. Table III shows clinicopathological characteristics of HPD cases and nonHPD cases in the nivolumab group. Comparing HPD cases and non-HPD cases in the nivolumab group, existing liver metastasis cases were more frequent in HPD cases than nonHPD cases. Human epidermal receptor 2 (HER2)-positive cases were tended to be more frequently in HPD cases than non-HPD cases. Moreover, NLR tended to be lower in HPD cases compared to non-HPD cases. NLR and PLR in HPD cases or non-HPD cases are shown in Figure 4. The median NLR was 2.4 (range=0.8-2.9) in HPD cases and 3.4 (range=1.2-9.2) in non-HPD cases. Of these, the lowest NLR case was a super HPD case, which we evaluated by immunological analysis. Comparing high NLR $(\geq 5)$ and low NLR $(<5)$, we used 5 as the NLR cut-off value according to

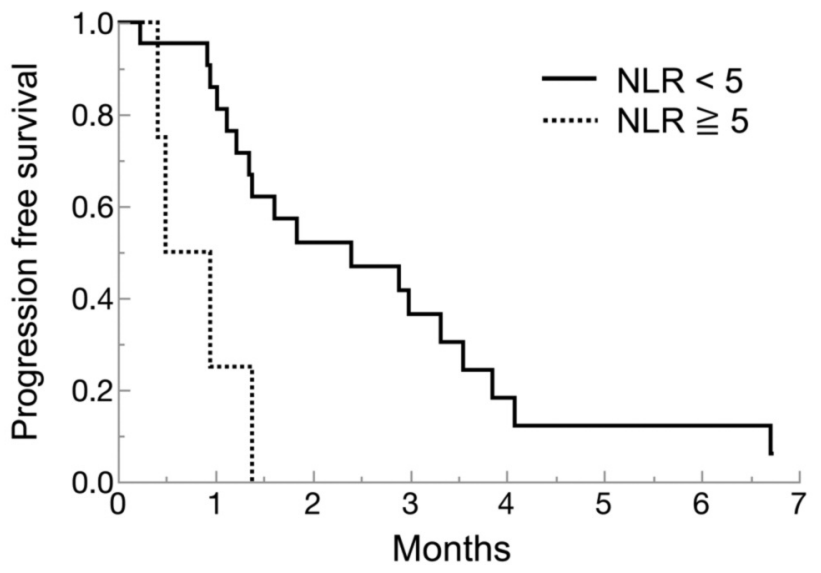

Figure 5. Progression-free survival by Neutrophil-lymphocyte ratio $(N L R)$ in the nivolumab group. The solid line showed NLR low $(<5)$, and the dotted line showed NLR high $(\geq 5)$.

previous study (15), for which the low NLR group showed significant longer PFS than high NLR (2.4 months vs. 0.7 months, $p=0.0035$ ) (Figure 5).

Genetic analysis for super HPD case using next generation sequencing $(N G S)$. In the exome sequence of a super HPD case, MDM2/4 amplification, EGFR aberration, and a JAK $1 / 2$ mutation were not found (data not shown).

\section{Discussion}

This is a retrospective observational study comparing nivolumab and irinotecan for HPD in patients with gastric cancer. Table IV shows previous HPD reports in solid tumor treated with ICI, of which only 2 non-small cell lung cancer cases, 2 solid tumor cases, and 2 gastric cancer cases were reported until now. Currently, TGK ratio of 2 or more is standard for HPD analysis, and recent studies of solid tumors treated with ICI revealed an HPD rate of 6-29\% using this criterion. We showed a $16.7 \%$ rate of HPD in patients with gastric cancer treated with irinotecan third-line therapy. This rate was consistent with our HPD rate of nivolumab (23.1\%). Considering the mechanism of HPD related to ICI, it is likely that drug-induced HPD will not occur using cytotoxic agents, such as irinotecan. These HPD cases in the irinotecan group were suspected to represent naturally rapidly growing disease cases. Because standard HPD criteria of TGK ratio of 2 or more includes these cases, we suggest that this criterion is not appropriate for HPD analysis.

In the ICI group of each clinical trial, the survival curves were shown to decrease immediately after the start of administration $(6,7)$. Therefore, ICI-induced HPD can occur; however, a considerable number of HPD cases 
Table IV. Previous HPD reports in solid tumors treated with ICI.

\begin{tabular}{|c|c|c|c|c|c|c|c|}
\hline & $\begin{array}{l}\text { Champiat } \\
\text { et al. }(8)\end{array}$ & $\begin{array}{c}\text { Kato } \\
\text { et al. }(9)\end{array}$ & $\begin{array}{l}\text { Saada-Bouzid } \\
\text { et al. (12) }\end{array}$ & $\begin{array}{l}\text { Ferrara } \\
\text { et al. }(10)\end{array}$ & $\begin{array}{l}\text { Lo Russo } \\
\text { et al. (11) }\end{array}$ & $\begin{array}{l}\text { Sasaki } \\
\text { et al. (13) }\end{array}$ & $\begin{array}{l}\text { Aoki M } \\
\text { et al. (14) }\end{array}$ \\
\hline Population & $\begin{array}{l}\text { Metastatic cancer } \\
\text { Phase } 1(\mathrm{~N}=131)\end{array}$ & $\begin{array}{c}\text { Metastatic cancer } \\
\quad(\mathrm{N}=155)\end{array}$ & $\begin{array}{l}\text { Head and neck } \\
\text { Cancer }(\mathrm{N}=34)\end{array}$ & $\begin{array}{l}\text { Non-small-cell } \\
\text { lung cancer } \\
(\mathrm{N}=406)\end{array}$ & $\begin{array}{l}\text { Non-small-cell } \\
\text { lung cancer } \\
(\mathrm{N}=187)\end{array}$ & $\begin{array}{c}\text { Gastric cancer } \\
\quad(\mathrm{N}=73)\end{array}$ & $\begin{array}{c}\text { Gastric cancer } \\
(\mathrm{N}=34)\end{array}$ \\
\hline HPD criteria & TGK ratio $>2$ & $\begin{array}{c}>50 \% \text { increase in } \\
\text { tumor burden } \\
>2 \text {-fold increase in } \\
\text { progression pace }\end{array}$ & TGK ratio $>2$ & TGK ratio $>2$ & $\begin{array}{c}>50 \% \text { increase } \\
\text { in } \mathrm{SLD}<6 \text { weeks } \\
\mathrm{TTF}<2 \text { months }\end{array}$ & TGK ratio $>2$ & $\begin{array}{l}\text { TGR more than } \\
\text { twofold }\end{array}$ \\
\hline HPD rate & $9 \%$ & $6 \%$ & $29 \%$ & $13.8 \%$ & $25.7 \%$ & $21 \%$ & $29.4 \%$ \\
\hline $\begin{array}{l}\text { Associated } \\
\text { factors }\end{array}$ & Age & $\begin{array}{l}\text { MDM2/MDM4 } \\
\text { EGFR }\end{array}$ & $\begin{array}{l}\text { Regional } \\
\text { recurrence }\end{array}$ & $\begin{array}{l}\text { Metastatic } \\
\text { sites }>2\end{array}$ & $\begin{array}{c}\text { CD33, CD163 } \\
\text { MDM2/MDM4 } \\
\text { EGFR }\end{array}$ & $\begin{array}{l}\text { ANC } \\
\text { CRP }\end{array}$ & - \\
\hline
\end{tabular}

HPD: Hyper-progressive disease; ICI: immune checkpoint inhibitor; TGK: tumor growth kinetics; MDM2: murine double minute 2; MDM4: murine double minute 4; EGFR: epidermal growth factor receptor; ANC: absolute neutrophil count; CRP: c-reactive protein.

defined by standard criteria may be represent naturally rapidly growing disease cases. Of HPD cases in our nivolumab group, only two cases satisfied the super HPD definition proposed in this study. In these two super HPD cases, tumor growth was clearly accelerated, and the survival was reduced by nivolumab administration. We believe that these super HPD cases were true HPD related to ICI administration. Therefore, it is important to predict these cases prior to ICI treatment.

HPD cases of gastric cancer have been retrospectively reported after the administration of nivolumab or irinotecan (14). A previous study revealed that the HPD rate was significantly higher in the nivolumab group (29.4\%) than the irinotecan group (13.5\%). Further, the HPD rate of nivolumab was $15.9 \%$ higher than irinotecan, partially indicating a true HPD. However, the researchers used a different definition of HPD, such as tumor growth rate (TGR), thus it is difficult to compare to our study. However, similar to our study, they observed HPD with conventional chemotherapy such as irinotecan.

Previous reports have reported that genetic abnormalities such as MDM2/4 amplification, EGFR aberration, and JAK $1 / 2$ mutation cause $\operatorname{HPD}(9,11)$. However, these gene abnormalities were not observed in the super HPD cases examined in this study. These genetic abnormalities are wellknown resistant markers of ICI. Because HPD cases defined by the standard HPD criterion include naturally rapidly growing disease cases. it is difficult to predict HPD cases using these abnormalities. We believe that super HPD that has been accelerated by ICI is different from HPD that occurs during the natural course. Therefore, further studies should be conducted on only super HPD cases to identify the gene alterations responsible for true HPD.
In our study, HPD cases tended to have low NLR, especially super HPD cases. Sasaki et al. retrospectively investigated 62 gastric cancer patients treated with nivolumab (13). In their study, NLR was significantly higher in HPD cases than non-HPD cases, which is distinct from our study. In fact, when the NLR cut-off value was set to 5 , the group with NLR of 5 or less had a significantly longer PFS than the group with 5 or more in our study (Figure 5). Although lower NLR is a good prognostic factor in general, it may not necessarily be a factor in HPD.

In this study, we performed immunological analysis using a super HPD case, normal HPD cases, and long SD cases, which showed that Treg cells were activated in super HPD cases. Cases with low NLR contained a significant number of original lymphocytes and may demonstrate a better effect of ICI. However, HPD may develop when the main lymphocyte is a regulatory $\mathrm{T}$ cell. In our study, immunological analyses revealed that there was no difference between HPD cases using normal criteria and long SD cases. Conversely, the super HPD case defined using our criteria demonstrated significant activation of regulatory $\mathrm{T}$ cells.

No definitive effect predictors for HPD have been reported so far, likely because the boundary between HPD, which was rapidly exacerbated by treatment, and $\mathrm{PD}$, which represents cancer exacerbation due to natural course, could not be differentiated using the conventional definition. Therefore, we proposed a redefinition of super HPD as a rapidly exacerbating HPD case with a TGK ratio of 5 or more and an increase in the number of tumors 2 times or more compared to the pre-baseline number of tumors, or a case in which peritoneal dissemination progressed rapidly and the patient was unable to eat within 2 weeks after nivolumab administration. Super HPD was not observed in HPD with 
irinotecan. TGK ratio of 5 or more is easily satisfied when the original tumor diameter is small. Therefore, the number of tumors was also added as evaluation items. Further, in patients who did not have measurable disease, we included ascites volume and symptoms associated with exacerbation of peritoneal dissemination. In our defined super HPD, no previously reported genetic abnormalities were found. However, super HPD had a very low NLR and high amount of regulatory $\mathrm{T}$ cells, which could be a predictor of efficacy. This is completely different from the conventional concept for NLR. Despite a high number of lymphocytes, a subset may block antitumor effects, resulting in poor prognosis, even if NLR is low. Regarding memory cells, the super HPD case had a large subset of Treg. In future studies, although it is very difficult to collect the sample from the patients with super HPD, a large cohort of these cases will be needed to identify simpler and more accurate biomarkers.

In conclusion, the HPD rate based on ICI treatment of gastric cancer was lower than that of existing reports, yet still present. To treat super HPD, its cause should be determined; however, no clear predictor of super HPD is known. In our super HPD case, AST/ALT increased and deterioration of general condition was rapidly observed 8 days after nivolumab administration. Thus, when a suspected symptom of HPD appears, it is necessary to evaluate tumor progression and cease treatment.

\section{Conflicts of Interest}

The Authors have no conflicts of interest to declare in relation to this study.

\section{Authors' Contributions}

YK analyzed and interpreted the patient data regarding gastric cancer. YK and YK were major contributors in the writing of the manuscript. TT contributed as an advisor to the overall research. All Authors read and approved the final manuscript.

\section{Acknowledgements}

The Authors would like to thank Manami Kobayashi and Editage (www.editage.com) for English language editing.

\section{References}

1 Topalian SL, Hodi FS, Brahmer JR, Gettinger SN, Smith DC, McDermott DF, Powderly JD, Carvajal RD, Sosman JA, Atkins MB, Leming PD, Spigel DR, Antonia SJ, Horn L, Drake CG, Pardoll DM, Chen L, Sharfman WH, Anders RA, Taube JM, McMiller TL, Xu H, Korman AJ, Jure-Kunkel M, Agrawal S, McDonald D, Kollia GD, Gupta A, Wigginton JM and Sznol M: Safety, activity, and immune correlates of anti-PD-1 antibody in cancer. N Engl J Med 366(26): 2443-2454, 2012. PMID: 22658127. DOI: 10.1056/NEJMoa1200690
2 Brahmer JR, Tykodi SS, Chow LQ, Hwu WJ, Topalian SL, Hwu P, Drake CG, Camacho LH, Kauh J, Odunsi K, Pitot HC, Hamid O, Bhatia S, Martins R, Eaton K, Chen S, Salay TM, Alaparthy S, Grosso JF, Korman AJ, Parker SM, Agrawal S, Goldberg SM, Pardoll DM, Gupta A and Wigginton JM: Safety and activity of anti-PD-L1 antibody in patients with advanced cancer. N Engl J Med 366(26): 2455-2465, 2012. PMID: 22658128. DOI: 10.1056/NEJMoa1200694

3 Kang YK, Boku N, Satoh T, Ryu MH, Chao Y, Kato K, Chung HC, Chen JS, Muro K, Kang WK, Yeh KH, Yoshikawa T, Oh SC, Bai LY, Tamura T, Lee KW, Hamamoto Y, Kim JG, Chin K, Oh DY, Minashi K, Cho JY, Tsuda M and Chen LT: Nivolumab in patients with advanced gastric or gastro-oesophageal junction cancer refractory to, or intolerant of, at least two previous chemotherapy regimens (ONO-4538-12, ATTRACTION-2): a randomised, double-blind, placebo-controlled, phase 3 trial. Lancet 390(10111): 2461-2471, 2017. PMID: 28993052. DOI: 10.1016/S0140-6736(17)31827-5

4 Fuchs CS, Doi T, Jang RW, Muro K, Satoh T, Machado M, Sun W, Jalal SI, Shah MA, Metges JP, Garrido M, Golan T, Mandala M, Wainberg ZA, Catenacci DV, Ohtsu A, Shitara K, Geva R, Bleeker J, Ko AH, Ku G, Philip P, Enzinger PC, Bang YJ, Levitan D, Wang J, Rosales M, Dalal RP and Yoon HH: Safety and Efficacy of Pembrolizumab Monotherapy in Patients With Previously Treated Advanced Gastric and Gastroesophageal Junction Cancer: Phase 2 Clinical KEYNOTE-059 Trial. JAMA Oncol 4(5): e180013, 2018. PMID: 29543932. DOI: 10.1001/ jamaoncol.2018.0013

5 Le DT, Durham JN, Smith KN, Wang H, Bartlett BR, Aulakh LK, Lu S, Kemberling H, Wilt C, Luber BS, Wong F, Azad NS, Rucki AA, Laheru D, Donehower R, Zaheer A, Fisher GA, Crocenzi TS, Lee JJ, Greten TF, Duffy AG, Ciombor KK, Eyring AD, Lam BH, Joe A, Kang SP, Holdhoff M, Danilova L, Cope L, Meyer C, Zhou S, Goldberg RM, Armstrong DK, Bever KM, Fader AN, Taube J, Housseau F, Spetzler D, Xiao N, Pardoll DM, Papadopoulos N, Kinzler KW, Eshleman JR, Vogelstein B, Anders RA and Diaz LA Jr: Mismatch repair deficiency predicts response of solid tumors to PD-1 blockade. Science 357(6349): 409-413, 2017. PMID: 28596308. DOI: 10.1126/science.aan6733

6 Shitara K, Özgüroğlu M, Bang YJ, Di Bartolomeo M, Mandalà M, Ryu MH, Fornaro L, Olesiński T, Caglevic C, Chung HC, Muro K, Goekkurt E, Mansoor W, McDermott RS, ShachamShmueli E, Chen X, Mayo C, Kang SP, Ohtsu A, Fuchs CS and KEYNOTE-061 investigators.: Pembrolizumab versus paclitaxel for previously treated, advanced gastric or gastro-oesophageal junction cancer (KEYNOTE-061): a randomised, open-label, controlled, phase 3 trial. Lancet 392(10142): 123-133, 2018. PMID: 29880231. DOI: 10.1016/S0140-6736(18)31257-1

7 Tabernero J, Van cutsem E, Bang Y, Fuchs C, Wyrwicz L, Lee K, Kudaba I, Garrido M, Chung H, Castro salguero H, Mansoor W, Braghiroli M, Goekkurt E, Chao J, Wainberg Z, Kher U, Shah S, Kang S and Shitara K: Pembrolizumab with or without chemotherapy versus chemotherapy for first-line treatment of advanced gastric or gastroesophageal junction (G/GEJ) adenocarcinoma: The Phase 3 KEYNOTE-062 Study. Annals of Oncology 30: iv152-iv153, 2020. DOI: 10.1093/annonc/ mdz183.001

8 Champiat S, Dercle L, Ammari S, Massard C, Hollebecque A, Postel-vinay S, Chaput N, Eggermont A, Marabelle A, Soria J and Ferté C: Hyperprogressive disease is a new pattern of 
progression in cancer patients treated by anti-PD-1/PD-L1. Clinical Cancer Research 23(8): 1920-1928, 2020. DOI: 10.1158/1078-0432.CCR-16-1741

9 Kato S, Goodman A, Walavalkar V, Barkauskas DA, Sharabi A and Kurzrock R: Hyperprogressors after Immunotherapy: Analysis of genomic alterations associated with accelerated growth rate. Clin Cancer Res 23(15): 4242-4250, 2017. PMID: 28351930. DOI: $10.1158 / 1078-0432 . C C R-16-3133$

10 Ferrara R, Mezquita L, Texier M, Lahmar J, Audigier-Valette C, Tessonnier L, Mazieres J, Zalcman G, Brosseau S, Le Moulec S, Leroy L, Duchemann B, Lefebvre C, Veillon R, Westeel V, Koscielny S, Champiat S, Ferté C, Planchard D, Remon J, Boucher ME, Gazzah A, Adam J, Bria E, Tortora G, Soria JC, Besse B and Caramella C: Hyperprogressive disease in patients with advanced non-small cell lung cancer treated with PD-1/PD-L1 inhibitors or with single-agent chemotherapy. JAMA Oncol 4(11): 1543-1552, 2018. PMID: 30193240. DOI: 10.1001/jamaoncol.2018.3676

11 Lo Russo G, Moro M, Sommariva M, Cancila V, Boeri M, Centonze G, Ferro S, Ganzinelli M, Gasparini P, Huber V, Milione M, Porcu L, Proto C, Pruneri G, Signorelli D, Sangaletti S, Sfondrini L, Storti C, Tassi E, Bardelli A, Marsoni S, Torri V, Tripodo C, Colombo MP, Anichini A, Rivoltini L, Balsari A, Sozzi G and Garassino MC: Antibody-Fc/FcR interaction on macrophages as a mechanism for hyperprogressive disease in non-small cell lung cancer subsequent to PD-1/PD-L1 blockade. Clin Cancer Res 25(3): 989-999, 2019. PMID: 30206165. DOI 10.1158/1078-0432.CCR-18-1390

12 Saâda-Bouzid E, Defaucheux C, Karabajakian A, Coloma VP, Servois V, Paoletti X, Even C, Fayette J, Guigay J, Loirat D, Peyrade F, Alt M, Gal J and Le Tourneau C: Hyperprogression during anti-PD-1/PD-L1 therapy in patients with recurrent and/or metastatic head and neck squamous cell carcinoma. Ann Oncol 28(7): 1605-1611, 2017. PMID: 28419181. DOI: 10.1093/ annonc/mdx 178
13 Sasaki A, Nakamura Y, Mishima S, Kawazoe A, Kuboki Y, Bando H, Kojima T, Doi T, Ohtsu A, Yoshino T, Kuwata T, Akimoto T and Shitara K: Predictive factors for hyperprogressive disease during nivolumab as anti-PD1 treatment in patients with advanced gastric cancer. Gastric Cancer 22(4): 793-802, 2019. PMID: 30627987. DOI: $10.1007 / \mathrm{s} 10120-018-00922-8$

14 Aoki M, Shoji H, Nagashima K, Imazeki H, Miyamoto T, Hirano H, Honma Y, Iwasa S, Okita N, Takashima A, Kato K, Higuchi $\mathrm{K}$ and Boku N: Hyperprogressive disease during nivolumab or irinotecan treatment in patients with advanced gastric cancer. ESMO Open 4(3): e000488, 2019. PMID: 31231567. DOI: 10.1136/esmoopen-2019-000488

15 Jung M, Ryu MH, Oh DY, Kang M, Zang DY, Hwang IG, Lee KW, Kim KH, Shim BY, Song EK, Sym SJ, Han HS, Park YL, Kim JS, Lee HW, Lee MH, Koo DH, Song HS, Lee N, Yang SH, Choi DR, Hong YS, Lee KE, Maeng CH, Baek JH, Kim S, Kim YH, Rha SY, Cho JY and Kang YK: Efficacy and tolerability of ramucirumab monotherapy or in combination with paclitaxel in gastric cancer patients from the expanded access program cohort by the Korean Cancer Study Group (KCSG). Gastric Cancer 21(5): 819-830, 2018. PMID: 29427038. DOI: 10.1007/s10120018-0806-1
Received December 10, 2020

Revised February 4, 2021

Accepted February 10, 2021 